
3 Research Square
Preprints are preliminary reports that have not undergone peer review.
They should not be considered conclusive, used to inform clinical practice, or referenced by the media as validated information.

\title{
A Bibliometric Analysis and Visualization of Current Research Trends in Traditional Chinese Medicine for Osteosarcoma
}

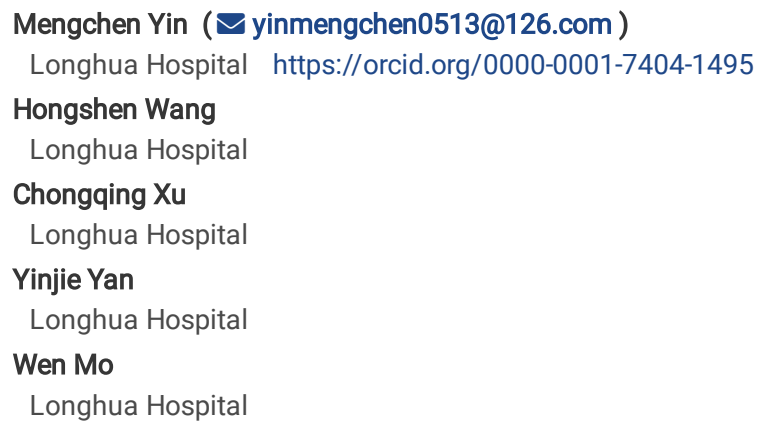




\section{Abstract}

Background: Osteosarcoma (OS), a most common malignant tumor arising from the bone, has a very high mortality and disability rate. Due to its multitargeted and multi-biologically active natural components, traditional Chinese medicine (TCM) has a good therapeutic efficacy and minimal side effects. So far, few analyses have summarized the researches of TCM treatment for OS. This study aimed to illustrate the research framework, overall knowledge structure, and development trends of TCM treatment for OS, using a bibliometric analysis and newly developed visualization tools.

Methods: Research datasets were acquired from the Web of Science (WOS) database and the time span was defined as "all years". Articles were tracked using the key words "osteosarcoma", "Traditional Chinese Medicine", "Traditional Chinese Medicine Formula", "Chinese Herb Formula" and "Chinese herbal drug". Moreover, VOS viewer and Citespace software was used to analyze the data and generate visualization knowledge maps. Annual trends of publications, distribution of institutes, distribution of journals, citation and H-Index status, co-authorship status, research hotspots and co-citation status were analyzed.

Results: After reading the abstract or the full text, 223 publications in the WOS database met the requirement. The number of published articles showed a rise but the citation frequency and the $\mathrm{H}$-index of China were relatively low. The cooperation between the countries, institutes and authors were relatively weak. Most publications were basic researches. Most previous researches focused on basic mechanisms of TCM in treating OS, and therapy and improvement of dosage form may become a frontier in this research field.

Conclusion: Compared with other fields, this field is still in infancy. The distribution of researches is imbalanced and cooperation between countries, institutions and authors remains to be strengthened. Furthermore, basic research occupies an absolute dominant position, and the exploration of the molecular mechanism of TCM in preventing and treating OS may become a key point in the future.

\section{Introduction}

Osteosarcoma (OS), a most common malignant tumor arising from the bone, accounts for $25 \%-35 \%$ of malignant bone tumors in children and young adults. OS has a very high mortality and disability rate, which brings heavy burdens to families and the society. The combination of neoadjuvant chemotherapy and limb salvage surgery is the standard treatment of OS and has significantly improved survival of OS patients over the past decades. To date, the 5 -year survival rate of OS patients has increased to $55-70 \%$. OS is highly invasive, with metastasis occurring in about $30 \%$ of patients, so the 5 -year survival for patients with metastatic disease is only $20 \% .{ }^{1-4}$ However, a considerable number of patients are either insensitive or resistant to chemotherapy. In addition, patients are still faced with recurrence and pulmonary metastasis that could lead to poor prognosis. Accordingly, it is urgent to develop novel or improved therapies for the treatment of OS.

Traditional Chinese medicine (TCM), featuring multi-targeted and multi-biologically active natural components, has shown good therapeutic efficacy and minimal side effects in tumor treatment. It can induce tumor cell differentiation, promote tumor apoptosis and anti-information transmission, reverse multidrug resistance and anti-metastasis and regulate biological responses. Because of its marked inhibitory effects on tumor growth, blood vessel formation and drug resistance of OS, TCM treatment of OS has become a research hotspot in recent years and played an increasingly important role in the comprehensive treatment of $0 S^{4-9}$.

Literature is essential in scientific research. Bibliometrics is a special quantitative and qualitative analysis to examine and describe large amounts of scientific literature. It uses mathematics, statistics, philology and other professional knowledge and methods to analyze the research achievements, the current distribution, subject development and research hotspots of a specific field. Finally it can provide visualized results. Bibliometric analysis has played a great role in policymaking and some scientific fields ${ }^{10-16}$, and now it is being gradually used in the study of diabetes, osteoarthritis, coronary heart disease and other medical fields.

To the best of our knowledge, no bibliometric analyses have explored the research situation, interdisciplinary nature and research hotspots regarding traditional Chinese medicine for OS. This study aimed to show the research framework, overall knowledge structure and development trends in the field of traditional Chinese medicine for the treatment of OS, using a bibliometric analysis and newly developed visualization tools. Hopefully, this study will help researchers better understand the research status, frontier trends and the current research interests and patterns in this field. In addition, it can also provide useful information and references for further investigation and publication.

\section{Materials And Methods}

\subsection{Search strategy and refined data}

The data for this study were collected from the Web of Science (WOS) and its Core Collection. WOS is a most widely accepted and suitable database for the subsequent bibliometric analysis of scientific publications due to its strict evaluation process and the most influential and credible information it could provide. Ethical approval was not needed since it was a systematic review.

The citations from Jan. 1, 1980 to Sep. 30, 2019 were gathered. The search terms were generated using the Entry Terms of the Mesh Database of the US National Library of Medicine, a thesaurus for cataloguing the diseases. Therefore, the completeness of the search query was guaranteed. The search terms were integrated as follows: "* Osteosarcoma* AND (*Traditional Chinese Medicine* OR *Traditional Chinese Medicine Formula* OR *Chinese Herb Formula* OR ${ }^{\star}$ Chinese herbal drug*)". The literature type was defined as "all types". To perfect the research, two independent researchers reviewed and evaluated the cited articles, respectively. Any different opinions were discussed until consensus was reached.

\subsection{Data analysis}

Page $2 / 22$ 
The following data were extracted and imported into Microsoft Excel 2017 (Microsoft, Redmond, WA, USA) for analysis: title, author's name, year of publication, citation number, country/region, institution, journal, number of references, type of article, study topic, study design and funding source. The following bibliometric parameters were also calculated: the quantity of papers, the number of citations, citation frequency per year, and $\mathrm{H}$-index.

VOS viewer (Eck and Waltman, Netherlands) is a software developed to construct and visualize co-occurrence networks of important terms extracted from both titles and abstracts of scientific literature. It has a powerful function in co-occurrence analysis and co-citation analysis. ${ }^{17,18}$ Citespace (Chaomei Chen, China) is used to obtain the quantitative information and visualize the networks utilizing various layouts in a specific field. ${ }^{19}$ In this study, we used VOS viewer to make co-authorship and co-citation networks, and then Citespace to create timeline view of the keywords.

\section{Results}

\subsection{The Current Status of Study}

A total of 230 studies were published till Sep. 2019. The inclusion conditions were refined and the abstract or the full text were read to reduce statistical bias. In total, 223 articles were selected using the search strategy reported above. The selection flow chart is shown in Fig. 1. Seven document types were found in these 223 publications. The most frequent document type was article (203), accounting for $91.03 \%$ of the total publications. Reviews (12) ranked the second with a proportion of $5.38 \%$. Chapters in books (3) ranked the third with a proportion of $1.35 \%$. Other document types included proceeding paper (2), editorial material (2) and meeting abstract (1). Table 1 lists the numbers of studies and proportions of each document type.

Table 1

Types of retrieved documents.

\begin{tabular}{|lll|}
\hline Type of document & Frequency & Proportion \\
\hline Article & 203 & $91.03 \%$ \\
\hline Review & 12 & $5.38 \%$ \\
\hline Book chapter & 3 & $1.35 \%$ \\
\hline Proceedings paper & 2 & $0.90 \%$ \\
\hline Editorial material & 2 & $0.90 \%$ \\
\hline Meeting abstract & 1 & $0.45 \%$ \\
\hline Total & 223 & $100 \%$ \\
\hline
\end{tabular}

\subsubsection{The Annual Trends of Publications}

Figure 2 plots the annual trends of publications. The first article was published in 2000, and a very slow increase was found in the following 8 years. There was a small peak in the number of studies in 2009 (10). Then, more and more scholars started to conduct research in this field, which led to a jump in the number of publications in 2017. A total of 35 articles were published in 2017, the highest number in all years. Considering the language barrier and lack of understanding about the TCM, OS-related articles were rarely published in international journals before 2009. Most articles were published in more recent years. In general, the number of articles published on the TCM treatment of OS showed an upward trend with a stable rise, indicating more and more efforts and exploration have been made on the role of TCM in the comprehensive treatment of OS.

\subsubsection{The Distribution of Institutes}

China Medical University (Taiwan) and Shanghai Jiao Tong University each had a total of 28 published papers, which was the greatest number among all the institutes, each accounting for $6.27 \%$ of all publications in this field. At the third position was Asia University Taiwan with 9 publications followed by the China Medical University Hospital Taiwan and China Pharmaceutical University. The top 10 institutes were all in China, with 5 in Chinese Mainland and 5 in Taiwan (Fig. 3). Altogether there were less than 100 papers related to TCM treatment for OS from the top 10 institutes, which implies the novelty of this research topic.

\subsubsection{The Distribution of Published Journals}

All the 223 publications were published in 128 journals. Only 38 (29.7\%) journals published more than 2 papers. In total, 63 (28.3\%) papers were published in the top 10 journals. The journal with the greatest number of publications was MOL MED REP, with a total of 11 papers. It was the only one journal that had published more than 10 papers. At the second position was ONCOL REP with 9 paper followed by INT J ONCOL and ONCOL LETT. The top 10 journals that published the most papers are showed in Fig. 4. As shown by Fig. 4, the articles on TCM treatment for OS were scattered, which is mainly because this is a new research field and a systematic hierarchy has not yet been formed.

\subsubsection{The Citation and H-Index Analysis}

The number of citations can reflect the quality of a paper. H-index is a reliable and authentic parameter for academic evaluation of the core scientists. According to the analysis of the data from WOS, all publications were cited for 3544 times. China had the largest number of citations (1438), accounting for $40.6 \%$ of the total citations. The USA ranked the second, with 405 citations followed by Taiwan, South Korea and Finland. China had a highest H-index of 21. 
The second highest was USA with an H-index of 11 followed by Taiwan, India and South Korea (Fig. 5, 6). China ranked the first in the number of articles published, the citation frequency and the H-index, respectively. The above results are not surprising as TCM is the characteristic medicine of China. But we must notice that the citation frequency and the $\mathrm{H}$-index of China were relatively low, which implies that the quality of the publications in China needs improvement.

\subsection{The Co-Authorship Analysis}

\subsubsection{The Country Co-Authorship Analysis}

Country co-authorship analysis is an important form of co-authorship analysis. It can reflect the degree of communication between countries as well as the influential countries in this field. Figure 7 demonstrates the country co-authorship network of publications. The various colors in the map shows the diversification of research directions. Bigger nodes represents more influence of the country. The links between nodes represents the cooperative relationships. The distance between the nodes and the thickness of the links reveals the level of cooperation among countries. China, USA and Taiwan were the top three influential countries of publications. But there was not much intersection among these countries. The biggest link strength was between China and USA, being 27. At the second position was the link between USA and India, being 26. At the third position was the link between China and India, being 25 . While the link strength between other countries was low. The result showed that the cooperation between the countries was relatively weak, indicating that the international collaboration needs to be strengthened.

\subsubsection{The Institute Co-Authorship Analysis}

The institute co-authorship analysis, another important form of co-authorship analysis, reflects the degree of communication among influential institutes. Figure 8 shows the institute co-authorship network of publications. Shanghai Jiao Tong University from China, China Medical University from Taiwan and the University Turku from Finland are the top three influential institutes of publications. Intersection among these institutes was also rare. The biggest link strength was between Shanghai Jiao Tong University and Asia University, being 97. The second strongest was the link between Shanghai Jiao Tong University and China Medical University Hospital, being 95. At the third position was the link between Asia University and China Medical University Hospital, being 72. The result showed that the cooperative relationship between the institutes was relatively weak, indicating that the international cooperation remains to be strengthened.

\subsubsection{The Highly Cited Publications}

Table 2 shows the 10 most influential papers in terms of title, journal, authors, publication year and citation numbers. Among them, 2 highly-cited studies were published in 2001-2005, 5 in 2005-2010 and 3 in 2011-2015. All the 10 papers were co-authored. The average number of authors is 8.3 . The mostly highlycited publication was written by Saleem A et al. with 217 citations. ${ }^{20}$ The paper of Li HY et al. occupied the second position with 101 citations. ${ }^{21}$ The publication written by $\mathrm{He} \mathrm{BC}$ et al. ranked the third with 91 citations. ${ }^{22}$ In addition, 3 publications were completed through cooperation between institutes. Only 1 publication was accomplished by international cooperation. This result indicates that it is necessary for authors to cooperate and the international coauthorship remains to be strengthened. 
Table 2

The top 10 papers with the most citations.

Title

Journal

Terminalia chebula Retz. fruit

Synthetic triterpenoids inhibit growth and induce apoptosis in human glioblastoma and neuroblastoma cells through inhibition of prosurvival Akt, JOURN NF-kappa B and Notch1 signaling

\subsection{The Keywords Analysis of Research Hotspots on Study}

Keywords co-occurrence can effectively reflect the research hotspots and provide support for the research. The keyword co-occurrence network is shown in Fig. 9. The bigger nodes and words generally show a larger weight of the keyword. The shorter distance reveals a stronger relation between two nodes. The thicker line indicates a more frequent co-occurrence of the two keywords. Table 3 showes the top 10 keywords with their frequencies and total link strengths. In Fig. 10, all keywords are visualized by VOS viewer for the revelation of the general structure. The keywords in red area appear more frequently; on the contrary, the keywords in green area appear less frequently. From Fig. 10, we can see the visualized research focuses. "Osteosarcoma" and "Apoptosis" turned out to be the core keywords. The closest relationships between "osteosarcoma" and "apoptosis" implied the research hotspots was the apoptosis mechanism of osteosarcoma cells.

Table 3

The top 10 keywords of the publications.

\begin{tabular}{|llll|}
\hline Rank & Keyword & Frequency & Total link strength \\
\hline 1 & osteosarcoma & 72 & 284 \\
\hline 2 & apoptosis & 68 & 279 \\
\hline 3 & proliferation & 11 & 49 \\
\hline 4 & invasion & 10 & 46 \\
\hline 5 & osteosarcoma cells & 9 & 32 \\
\hline 6 & autophagy & 8 & 32 \\
\hline 7 & cytotoxicity & 8 & 29 \\
\hline 8 & migration & 8 & 39 \\
\hline 9 & anticancer & 7 & 29 \\
\hline 10 & metastasis & 7 & 34 \\
\hline
\end{tabular}

There were 16 clusters for 390 keywords with high-frequency in the field. The cluster name was refined according to the keywords contained in each cluster, as shown in Table 4. Cluster 0 was related to cyclooxygenase; Cluster 1 was related to histone deacetylase inhibitor and Cluster 2 focused on biodistribution. All 
clusters are visualized in Fig. 11 with each color representing one cluster. The cluster analysis concluded that the main research field at present was how Chinese medicine monomer blocked the growth cycle of tumor cells, inhibited the rapid proliferation of tumor cells, and induced apoptosis of tumor cells.

Table 4

16 clusters of research

\begin{tabular}{|c|c|c|c|c|}
\hline $\begin{array}{l}\text { Cluster } \\
\text { ID }\end{array}$ & Size & Silhouette & mean(Year) & Label (TFIDF) \\
\hline 0 & 58 & 0.83 & 2005 & $\begin{array}{l}\text { (17.26) cyclooxygenase 2; (15.35) cyclooxygenase } 2 \text { expression; (14.7) triterpenoid; (14.34) } 9 \text { dien } 28 \text { oic } \\
\text { acid; (14.34) acute myelogenous leukemia }\end{array}$ \\
\hline 1 & 37 & 0.909 & 2010 & $\begin{array}{l}\text { (12.99) histone deacetylase inhibitor; (12.43) p21(waf1/c1p1); (12.43) phase ii; (12.43) cryptolepine; (12.43) } \\
\text { waf1/cip1 gene promoter }\end{array}$ \\
\hline 2 & 35 & 0.901 & 2009 & $\begin{array}{l}\text { (12.43) biodistribution; (12.43) fullerol; (12.43) fullerene derivative; (12.43) tumor-bearing mice; (12.43) } \\
\text { photodynamic therapy (pdt) }\end{array}$ \\
\hline 3 & 34 & 0.903 & 2011 & (12.99) aloin; (12.99) osteogenesis; (11.81) aloe emodin; (11.78) anticancer drug; (11.78) rhus verniciflua \\
\hline 4 & 31 & 0.871 & 2011 & (12.42) trial; (11.78) clinical pharmacology; (11.51) as2o3; (11.51) prognostic factor; (11.51) mnng \\
\hline 5 & 29 & 0.881 & 2009 & (17.45) p glycoprotein; (16.41) monoclonal antibody; (15.67) glycoprotein; (15.35) tumor cell; (14.7) mdr \\
\hline 6 & 28 & 0.815 & 2006 & (13.16) p21; (12.68) wild type p53; (12.68) transformed cell; (12.68) p21/waf1; (12.68) bark extract \\
\hline 7 & 28 & 0.909 & 2011 & $\begin{array}{l}\text { (13.49) rheumatoid arthriti; (12.99) emblica officinali; (10.07) matrix metalloproteinase (mmp) 13; (10.07) } \\
\text { osteoporosis; (10.07) emblica officinalis gaertn }\end{array}$ \\
\hline 8 & 19 & 0.966 & 2010 & $\begin{array}{l}\text { (12.99) blood glucose; (12.99) plant saponin; (12.99) furostanol saponin; (12.99) foodstuff; (12.99) volatile } \\
\text { constituent }\end{array}$ \\
\hline 9 & 19 & 0.92 & 2012 & (15.04) c myc; (14.34) cyclin; (14.34) d1; (13.93) alpinumisoflavone; (13.93) abyssinone v 4'-methyl-ether \\
\hline 10 & 18 & 0.936 & 2011 & $\begin{array}{l}\text { (8.93) colon cancer; (8.48) rabdosia rubescen; (8.48) studies invivo; (8.48) oridonin; (8.48) mitogen } \\
\text { activated protein kinasepathway }\end{array}$ \\
\hline 11 & 17 & 0.812 & 2014 & (10.27) tumor growth; (8.85) nucleoside; (8.48) bufalin; (8.48) in vivo; (7.28) cinobufagin \\
\hline 12 & 11 & 0.976 & 2008 & $\begin{array}{l}\text { (12.99) induceddifferentiation; (12.99) tumor suppressor protein; (12.99) npm; (12.99) translocation; (12.99) } \\
\text { b23 }\end{array}$ \\
\hline 13 & 10 & 0.984 & 2017 & $\begin{array}{l}\text { (19.57) synthesis; (16.41) silver; (16.41) light scattering; (15.04) antibacterial activity; (14.7) silver } \\
\text { nanoparticle }\end{array}$ \\
\hline 14 & 9 & 0.919 & 2009 & $\begin{array}{l}\text { (8.85) radix angelicae sinensis; (8.85) galectin 9; (8.85) astragali; (8.33) estrogen receptor alpha; (8.04) } \\
\text { receptor beta }\end{array}$ \\
\hline 15 & 7 & 1 & 2010 & $\begin{array}{l}\text { (15.35) soy isoflavone; (12.43) postmenopausal women; (12.43) bone los; (12.43) early; (12.43) mc3t3 e1 } \\
\text { cell }\end{array}$ \\
\hline
\end{tabular}

Table 5 shows 26 keywords with the strongest citation burst. The red and blue bars represented the frequently-and infrequently-cited keywords, respectively. All the 26 keywords represented the research frontiers of TCM treatment for OS. In addition, the frequencies of these 26 keywords were 304 , showing that $6.43 \%(26 / 404)$ of keywords accounted for $17.65 \%$ (304/1722) of the total 1722 frequencies. Figure 12 visualizes the timeline of 26 keywords, showing the evolution of the topic over time. 
Table 5

Top 26 Keywords with Strongest Citation Bursts

\begin{tabular}{|c|c|c|c|c|}
\hline Keywords & Strength & Begin & End & $2000-2019$ \\
\hline p53 & 3.6717 & 2000 & 2008 & 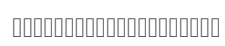 \\
\hline diosgenin & 2.6917 & 2004 & 2009 & 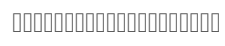 \\
\hline trigonella foenum graecum & 1.6515 & 2008 & 2011 & 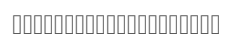 \\
\hline osteosarcoma cell & 1.7738 & 2008 & 2009 & 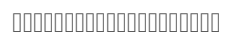 \\
\hline induction & 1.6047 & 2009 & 2013 & 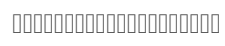 \\
\hline colon cancer & 1.5659 & 2009 & 2012 & 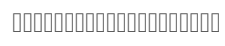 \\
\hline gene expression & 1.7414 & 2009 & 2010 & 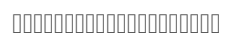 \\
\hline $\mathrm{mmp} 2$ & 1.8985 & 2012 & 2014 & 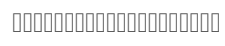 \\
\hline bcl 2 & 1.8524 & 2013 & 2015 & 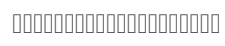 \\
\hline bax & 1.7354 & 2013 & 2015 & 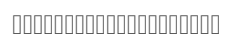 \\
\hline inhibition & 2.4033 & 2013 & 2014 & 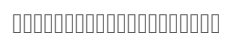 \\
\hline drug resistance & 2.1425 & 2013 & 2015 & 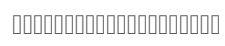 \\
\hline human osteosarcoma & 1.6412 & 2014 & 2015 & 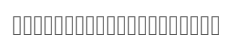 \\
\hline induced apoptosis & 1.6499 & 2014 & 2015 & 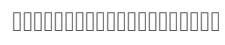 \\
\hline beta catenin & 1.8425 & 2015 & 2016 & 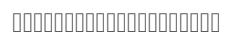 \\
\hline migration & 1.5928 & 2015 & 2016 & 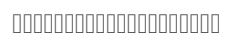 \\
\hline anticancer & 1.723 & 2016 & 2019 & 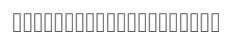 \\
\hline cancer therapy & 1.7749 & 2016 & 2017 & 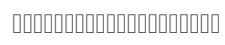 \\
\hline inflammation & 1.5244 & 2016 & 2017 & 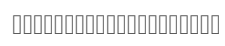 \\
\hline silver nanoparticle & 1.7276 & 2016 & 2019 & 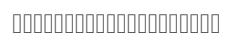 \\
\hline gastric cancer & 1.7749 & 2016 & 2017 & 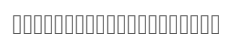 \\
\hline cell cycle & 1.5244 & 2016 & 2017 & 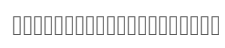 \\
\hline traditional chinese medicine & 2.2922 & 2017 & 2019 & 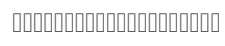 \\
\hline cell line & 1.6032 & 2017 & 2019 & 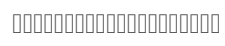 \\
\hline autophagy & 2.285 & 2017 & 2019 & 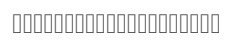 \\
\hline human osteosarcoma cell & 1.813 & 2017 & 2019 & 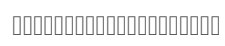 \\
\hline
\end{tabular}

As shown in Fig. 12, the studies from 2000 to 2005 mainly focused on arrest, apoptosis, expression, and proliferation, indicating that the researchers paid more attention to the regulation of the occurrence and development of tumor cells in this period. From 2006 to 2011, the representative burst keywords were chemotherapy, anticancer and different pathologic types of tumor, suggesting the transition from basic research to clinical research. The key words in the upper right corner of the timeline view were cancer therapy and silver nanoparticle, indicating that therapy and improvement of dosage form might become a frontier in the research of TCM treatment for OS, a shift from the previous basic mechanism research.

\subsection{The Co-Citation Analysis on Publications}

\subsubsection{The Reference Co-Citation Analysis}

Reference co-citation analysis is used to detect the structure and characteristics of a specific domain. In the reference co-citation network, the importance of nodes illustrates the research themes that are closely related to the research field. The betweenness centrality (BC) measures the importance of nodes in a network. Figure 13 shows the reference co-citation network TCM treatment for OS of 769 nodes, the biggest node being Murdoch MIRABELLO L (2009) follow by OTTAVIANI G (2009) and CORBIERE C (2003). ${ }^{23-25}$ The result indicted that there wasn't an obvious study closely related to the research field.

\subsubsection{The Journal Co-Citation Analysis}

The journal co-citation analysis can reveal not only the structure and characteristics of a subject, but also the overall structure and the characteristics of a journal. Figure 14 shows a journal co-citation network of 144 nodes. The biggest node was CANCER RES (2002) follow by CANCER LETT (2002) and J BIOL CHEM (2003). This result indicted that there lacked an obvious journal closely related to the research field in all these journals. 


\subsubsection{The Author Co-Citation Analysis}

Figure 15 shows the journal co-citation network of 753 nodes. The biggest node was ZHANG Y (2012) follow by MIRABELLO L (2014) and MOALIC S2013). The result indicted that no author is closely related to the research field in all these authors.

\section{Discussion}

Bibliometric analysis is a tool to quantify the characteristics and scholarly impact of citation classics. Understanding the characteristics of highly cited studies in a journal may help authors who wish to submit and publish effectively. It is the most widely accepted method to assess the merits of a specific field. ${ }^{26-28}$

Our study encompasses several notable strengths. To our knowledge, this is the first to analyzed the quality and quantity of studies on TCM treatment for OS in the world. To guarantee the comprehensiveness of the publication, we conducted a systematic literature search in the WOS database, because WOS could offer a powerful analysis of data from various aspects with a high recognition, a powerful uniform citation rate and significant impacts on journals. More than 1,000 articles were obtained when using "osteosarcoma", "Traditional Chinese Medicine" and "Traditional Chinese Medicine Formula" as the keywords. Finally, a total of 223 articles were screened out after reading the abstract or the full text.

Chinese medicine has existed in China for thousands of years; countless studies have been conducted by scholars of Chinese medicine. The TCM Formula (TCMF) which often contains several herbal components, was not quite accepted in the Western world in early years, so studies on TCMF were not favored in international journals. Yet in recent years, due to the constant support by the Chinese government and Tu Youyou's extraordinary achievement in artemisinin, together with China's rapid development in economyand scientific research, the study of TCM has been gradually accepted worldwide. ${ }^{29}$ WHO has asserted that Traditional Medicine is one of the primary sources of healthcare. ${ }^{30}$

In our study, the result showed a stable rise in the number of articles published on TCM treatment for OS in recent years, especially from 2009 to 2019 . The number of publications peaked in 2017. This trend indicates that TCM research has been improved greatly and attracted more attention in the global medical community. But the number of publications or citations on TCM treatment for OS is relatively small compared with other research fields, indicating this research field is still in infancy and needs long-term development and exploration. This study revealed the distribution of research on TCM treatment for OS was imbalanced. From the perspective of the countries and regions, China, the USA and Taiwan occupied the most dominant positions in this field. TCM research requires a large amount of financial and human resource. Apparently, the economic foundation plays an important role in scientific research. Therefore, countries with good economic conditions are also relatively advanced in scientific research. From the perspective of the institution, the top institutions are in China, which further illustrates that China holds the strongest research forces.

The top 10 cited articles were published between 2002 and 2015, which is consistent with the recent citation analyses. The article with the highest total citations (217) was published in 2002. But an obviously increase of total citations or high-quality articles did not appear in recent years. Co-authorship research is an important content of bibliometrics and the level of research collaboration is an index to assess the current research status. Authors, institutions and countries are the main aspects of the research cooperative relationship. The results of cooperative relationship network map analysis revealed that the centrality value was not high, nor was the density of cooperative relationship. The interaction between countries or institutions was also poor. Therefore, it is urgent to strengthen the international academic cooperation between countries/regions and institutions. Furthermore, forming an academic community is beneficial to the development of research in the future.

According to the types of research included, basic research occupies an absolutely dominant position, indicating that basic research is still the main stream of TCM treatment for OS. This result is consistent with the situation in the global community. The possible reason is that the characteristics of OS, such as low clinical incidence and high mortality, hinders the researchers from conducting high-quality clinical research. Through the co-occurrence and cluster analysis of the literature, it was found that the research in this field mainly focused on blocking the growth cycle of tumor cells, as well as inhibiting the rapid proliferation and apoptosis of tumor cells. It should be pointed out that the TCM formula often has multiple herbal components, making its composition characteristics, physical and chemical properties, pharmacodynamics and toxicology rather complex. Therefore, how TCM monomer regulates cell proliferation and apoptosis in OS is a hotspot of this field. In addition, basic researches are mostly vitro cell experiments, and there is still a big gap between the animal models and the actual clinical conditions. In general, the basic research on TCM treatment for OS is still in the exploration stage. Although certain progress has been made in recent years, it is still in its infancy. With the advancement in science and technology, the molecular mechanism of TCM in preventing and treating OS may become a key point in the future. It is also undeniable that researchers with outstanding influence and contributions are scarce in this field now. Furthermore, the lack of theoretical research is the bottleneck that causes the lag of clinical research on TCM treatment for OS. Thus, a breakthrough lies in the improvement in the above-mentioned aspects.

This study also has some limitations. First, bibliometric analyses only contain the published literature in PubMed and the unpublished works, including dissertations, reports or government documents, were not included. Besides, the delay of the PubMed indexation may account for the slight difference in the results retrieved. Therefore, the citation number may not fully reflect the impact of one article although it has been used widely. Second, all citations were treated in the same way whether it was cited for its positive contribution or for its negative impact or poor quality. Different authors employed differed levels of care in compiling references and differences in citation tracking across databases remained a concern. Also the authors might tend to cite papers from the journals in which they hoped to publish their research. So, caution must be employed in evaluating the quality of the research output solely on the basis of bibliometric data. As any statistical endeavor, bibliometric analyses have the potential to generate misleading and biased results. Third, bibliometric analyses can only provide a rough overview of trends in research and publishing. The input data were extracted using an elaborate search string, but might still have included irrelevant or duplicate titles, and might have missed pertinent publications with unspecific titles. Despite these limitations, our study provided some insights into the characteristics of researches and citation of articles published in the field of TCM treatment for OS.

Page $8 / 22$ 
Conclusion

In this study, bibliometric analysis was performed on the research of TCM treatment for OS using the visualization tools. The number of articles published showed an upward trend with a stable rise in recent years. But the research in this field was still in infancy. The distribution of research was imbalanced and there was poor interaction between countries/regions, institutions and authors. Therefore, it is urgent to strengthen the international academic cooperation. Furthermore, basic research occupied an absolutely dominant position. We hope scholars could diversify the research contents, extend the horizon and deepen the research in this field. The exploration of the molecular mechanism of TCM in preventing and treating OS may become a key point in the future. Moreover, with the further development and application of TCM, it is reasonable to believe that TCM research on OS will continue to grow in future.

\section{Abbreviations}

TCM

traditional Chinese medicine

WOS

Web of Science

\section{Declarations}

\section{Ethics approval and consent to participate}

Not applicable.

\section{Consent for publication}

Not applicable.

\section{Availability of data and material}

The datasets used and/or analyzed during the current study are available from the corresponding author on reasonable request.

\section{Competing interests}

Not applicable.

\section{Funding}

This work was sponsored by research grants from the Research Project of Shanghai Science and Technology Commission (201940231).

Authors' contributions

YMC, WHS, and XCQ are co-first authors of this manuscript, contributing equally to the design, and drafting of the manuscript. All authors participated in the design of the study. MW is co-corresponding author of this manuscript.

\section{Acknowledgements}

The authors declare that they have no competing interests

\section{References}

1. Wang W, Hu S, Chang J, et al. Down-Regulated microRNA-34a Expression as a Prognostic Marker for Poor Osteosarcoma in Mice: A Systematic Review and Meta-Analysis. J Cancer. 2018;9(22):4179-4186.

2. Tan GJS, Gerrand CH, Rankin KS. Blood-borne biomarkers of osteosarcoma: A systematic review. Pediatr Blood Cancer. Jan 2019;66(1):e27462.

3. Tamura T, Suzuki K, Yasuda T, et al. Extraskeletal osteosarcoma arising in the subcutaneous tissue of the lower leg: A case report and literature review. Mol Clin Oncol. Sep 2018;9(3):287-292.

4. Fu Y, Yu W, Cai H, Lu A. Forecast of actin-binding proteins as the oncotarget in osteosarcoma - a review of mechanism, diagnosis and therapy. Onco Targets Ther. 2018;11:1553-1561.

5. Chang JL, Wang WY, Li YM, et al. Chinese Herbal Medicine for Osteosarcoma in the Mouse: A Systematic Review and Meta-Analysis. Chin J Integr Med. May 2019;25(5):370-377.

6. Xiangyong Y, Zhongsheng Y, Wenchao L, et al. External application of traditional Chinese medicine in the treatment of bone cancer pain: a meta-analysis. Support Care Cancer. Jan 2016;24(1):11-17.

7. Di Genova L, Perruccio K, Celani MG, et al. Chemotherapy-Related Encephalopathy With Super-Refractory Status Epilepticus in a Child With Osteosarcoma: A Case Report With a Review of Literature. Front Pharmacol. 2019;10:963.

8. Koehn FE, Carter GT. The evolving role of natural products in drug discovery. Nat Rev Drug Discov. Mar 2005;4(3):206-220.

9. Mishra BB, Tiwari VK. Natural products: an evolving role in future drug discovery. Eur J Med Chem. Oct 2011;46(10):4769-4807. 
10. Valderrama-Zurian JC, Castello-Cogollos L, Aleixandre-Benavent R. Trends in scientific research in Insights into Imaging: a bibliometric review. Insights Imaging. Aug 28 2019;10(1):79.

11. Zhang TS, Qin HL, Wang T, et al. Global publication trends and research hotspots of nonalcoholic fatty liver disease: a bibliometric analysis and systematic review. Springerplus. 2015;4:776.

12. Boyce R, Rosch R, Finlayson A, et al. Use of a bibliometric literature review to assess medical research capacity in post-conflict and developing countries: Somaliland 1991-2013. Trop Med Int Health. Nov 2015;20(11):1507-1515.

13. Sun J, Wang MH, Ho YS. A historical review and bibliometric analysis of research on estuary pollution. Mar Pollut Bull. Jan 2012;64(1):13-21.

14. Ergul S, Ardahan M, Temel AB, Yildirim BO. Bibliometric review of references of nursing research papers during the decade $1994-2003$ in Turkey. Int Nurs Rev. Mar 2010;57(1):49-55.

15. Hu J, Ma Y, Zhang L, Gan F, Ho YS. A historical review and bibliometric analysis of research on lead in drinking water field from 1991 to 2007. Sci Total Environ. Mar 1 2010;408(7):1738-1744.

16. McLean R, Mendis K, Harris B, Canalese J. Retrospective bibliometric review of rural health research: Australia's contribution and other trends. Rural Remote Health. Oct-Dec 2007;7(4):767.

17. van Eck NJ, Waltman L. Software survey: VOSviewer, a computer program for bibliometric mapping. Scientometrics. Aug 2010;84(2):523-538.

18. Fajardo-Ortiz D, Duran L, Moreno L, Ochoa H, Castano VM. Mapping knowledge translation and innovation processes in Cancer Drug Development: the case of liposomal doxorubicin. $J$ Transl Med. Sep 3 2014;12:227.

19. Chen C, Hu Z, Liu S, Tseng H. Emerging trends in regenerative medicine: a scientometric analysis in CiteSpace. Expert Opin Biol Ther. May 2012;12(5):593608.

20. Saleem A, Husheem M, Harkonen P, Pihlaja K. Inhibition of cancer cell growth by crude extract and the phenolics of Terminalia chebula retz. fruit. $J$ Ethnopharmacol. Aug 2002;81(3):327-336.

21. Li HY, Zhang J, Sun LL, et al. Celastrol induces apoptosis and autophagy via the ROS/JNK signaling pathway in human osteosarcoma cells: an in vitro and in vivo study. Cell Death Dis. Jan 22 2015;6:e1604.

22. He BC, Gao JL, Zhang BQ, et al. Tetrandrine inhibits Wnt/beta-catenin signaling and suppresses tumor growth of human colorectal cancer. Mol Pharmacol. Feb 2011;79(2):211-219.

23. Mirabello L, Troisi RJ, Savage SA. Osteosarcoma incidence and survival rates from 1973 to 2004: data from the Surveillance, Epidemiology, and End Results Program. Cancer. Apr 1 2009;115(7):1531-1543.

24. Ottaviani G, Jaffe N. The etiology of osteosarcoma. Cancer Treat Res. 2009;152:15-32.

25. Corbiere C, Liagre B, Bianchi A, et al. Different contribution of apoptosis to the antiproliferative effects of diosgenin and other plant steroids, hecogenin and tigogenin, on human 1547 osteosarcoma cells. Int J Oncol. Apr 2003;22(4):899-905.

26. Liu YH, Wang SQ, Xue JH, et al. Hundred top-cited articles focusing on acute kidney injury: a bibliometric analysis. BMJ Open. Jul 27 2016;6(7):e011630.

27. Paris G, De Leo G, Menozzi P, Gatto M. Region-based citation bias in science. Nature. Nov 19 1998;396(6708):210.

28. Allen L, Jones C, Dolby K, Lynn D, Walport M. Looking for landmarks: the role of expert review and bibliometric analysis in evaluating scientific publication outputs. PLoS One. Jun 18 2009;4(6):e5910.

29. Schlagenhauf P. A tribute to Youyou Tu and artemisinin. Travel Med Infect Dis. Nov-Dec 2015;13(6):513-514.

30. Chen YB, Tong XF, Ren J, Yu CQ, Cui YL. Current Research Trends in Traditional Chinese Medicine Formula: A Bibliometric Review from 2000 to 2016 . Evid Based Complement Alternat Med. 2019;2019:3961395.

\section{Figures}




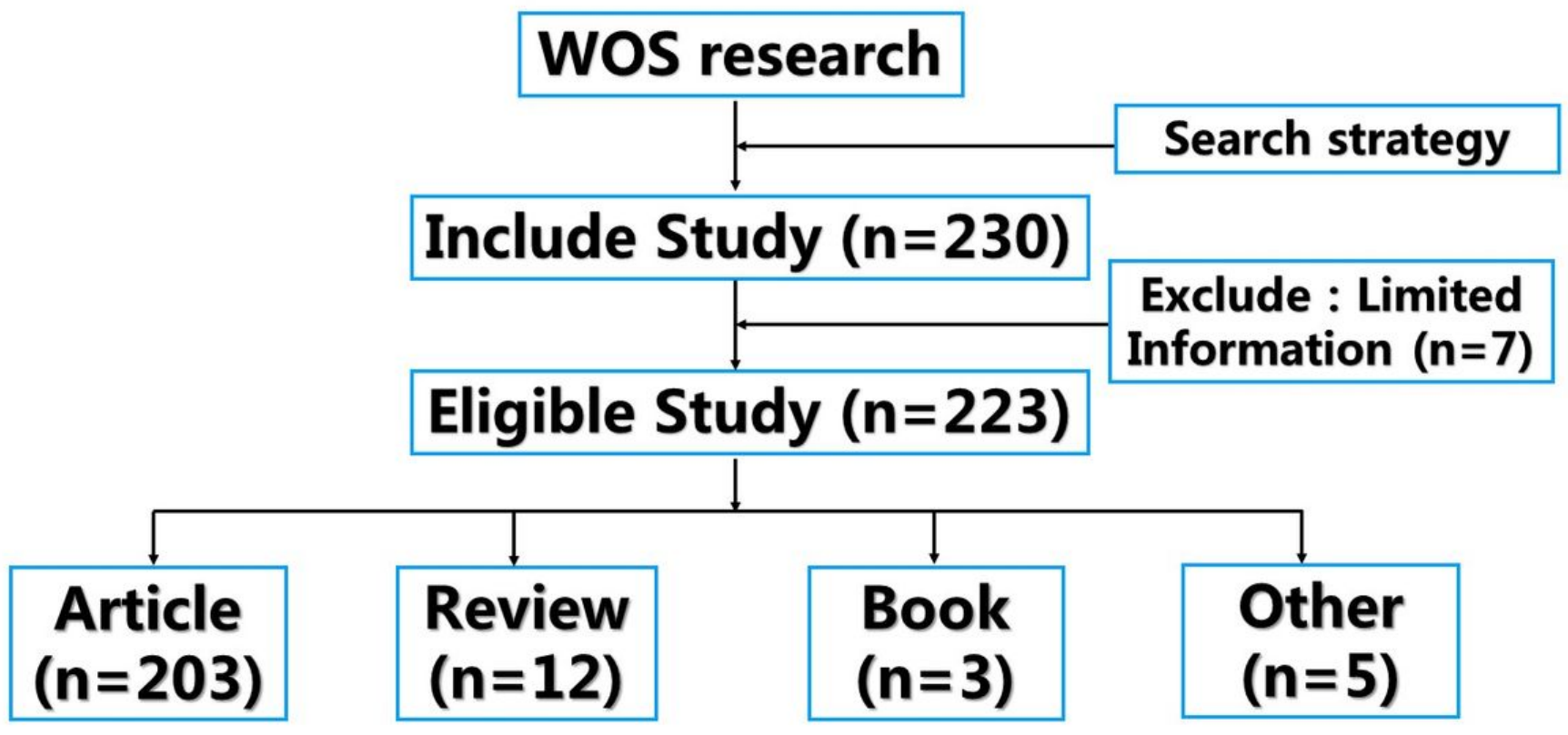

Figure 1

Flow chart 


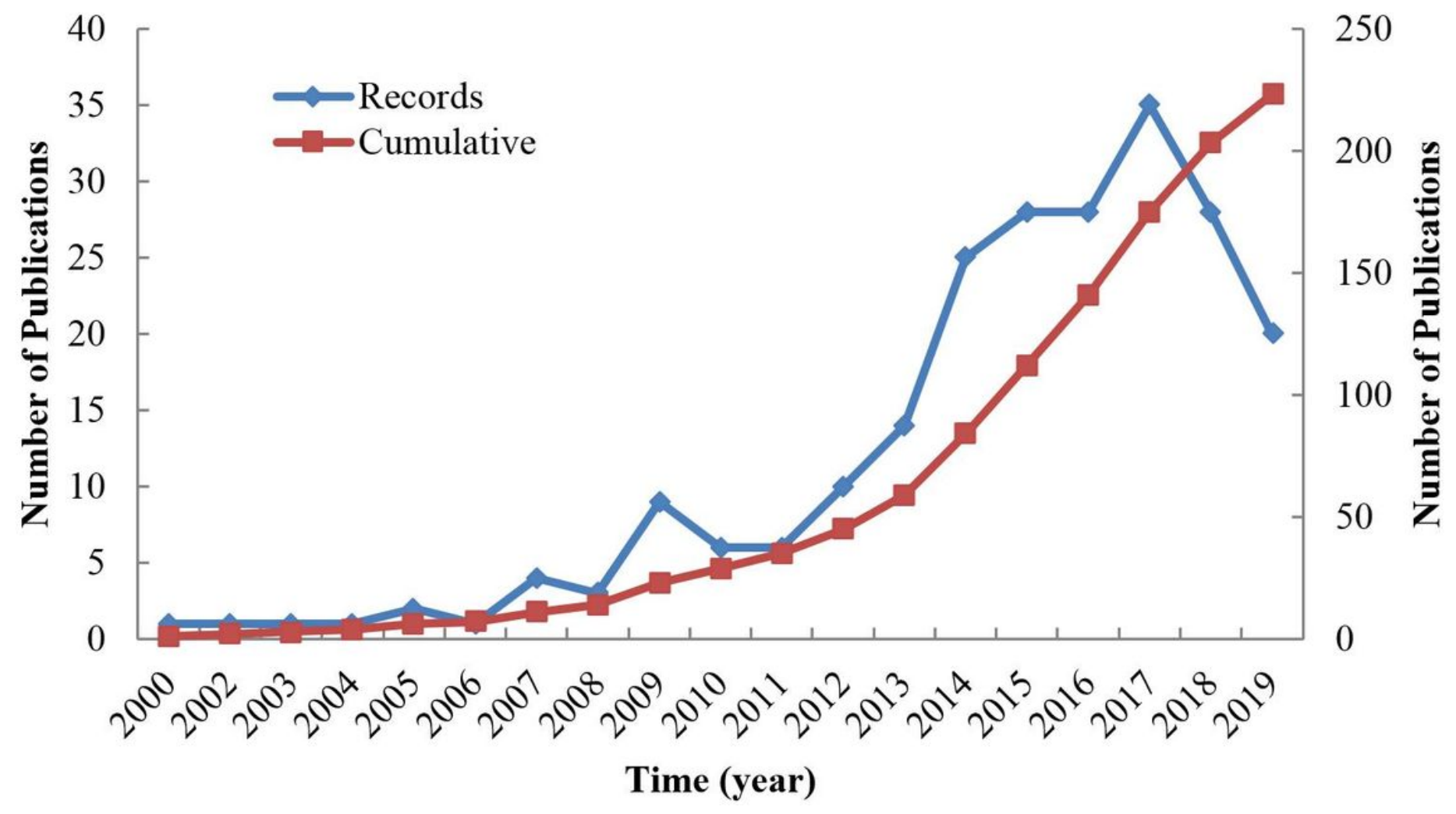

Figure 2

The annual trends of publications

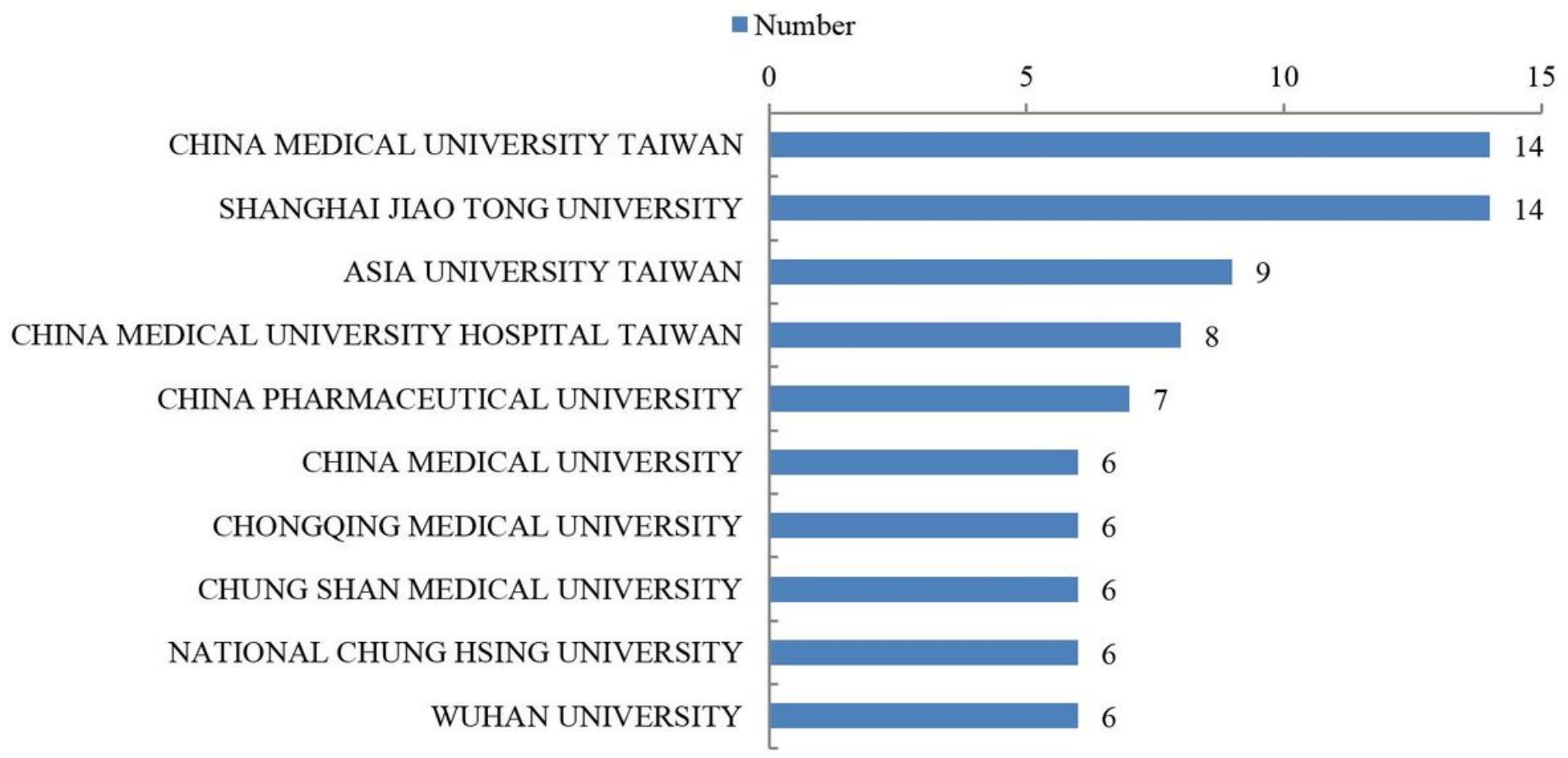

Figure 3

The top 10 institutes with publications 


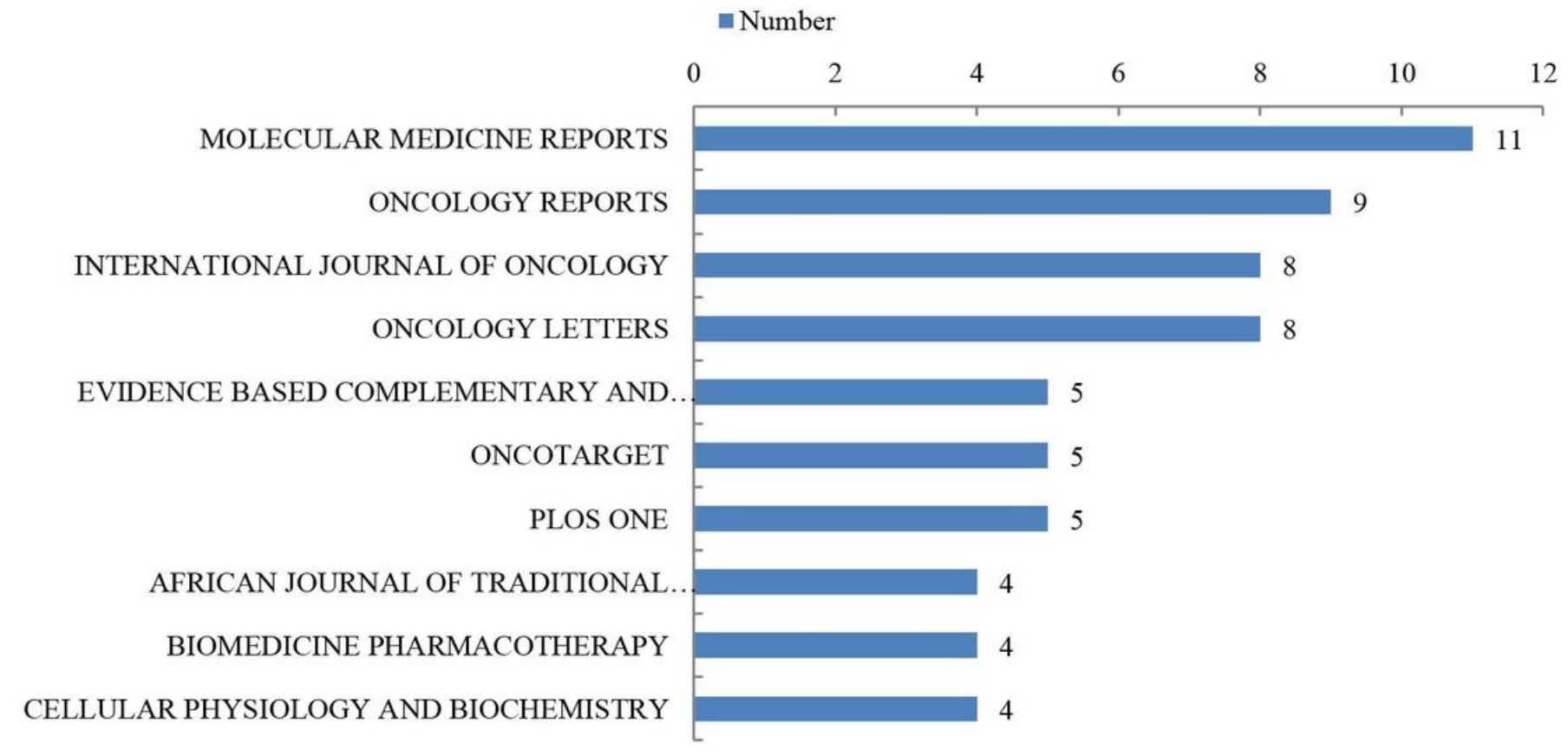

Figure 4

The top 10 journals with publications

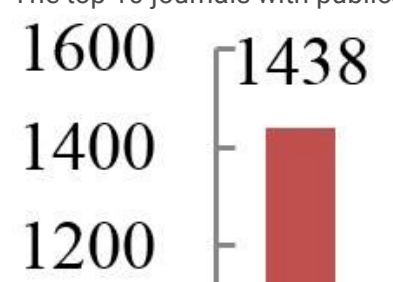

1000

800

600
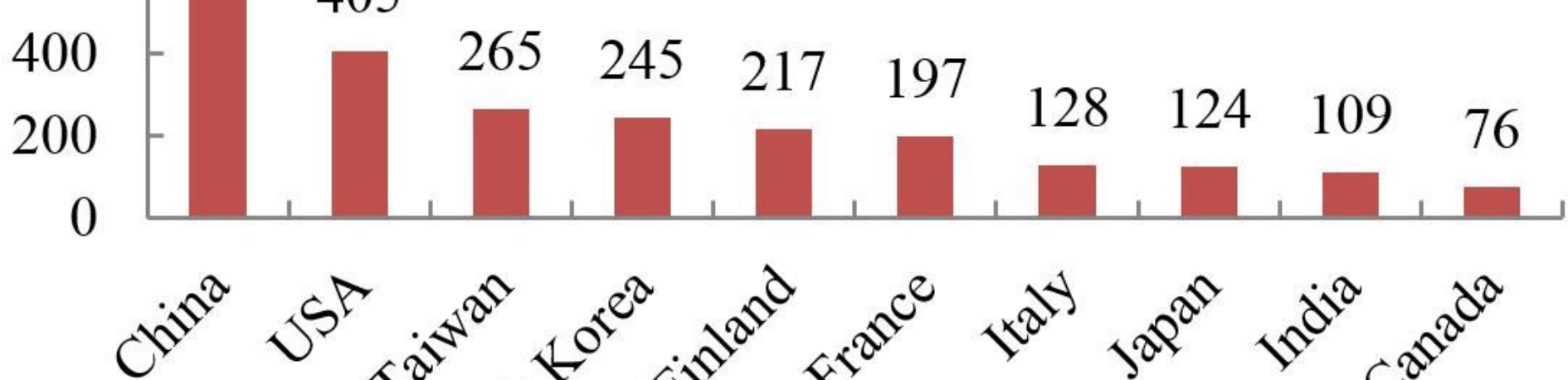

- Sum of citations 


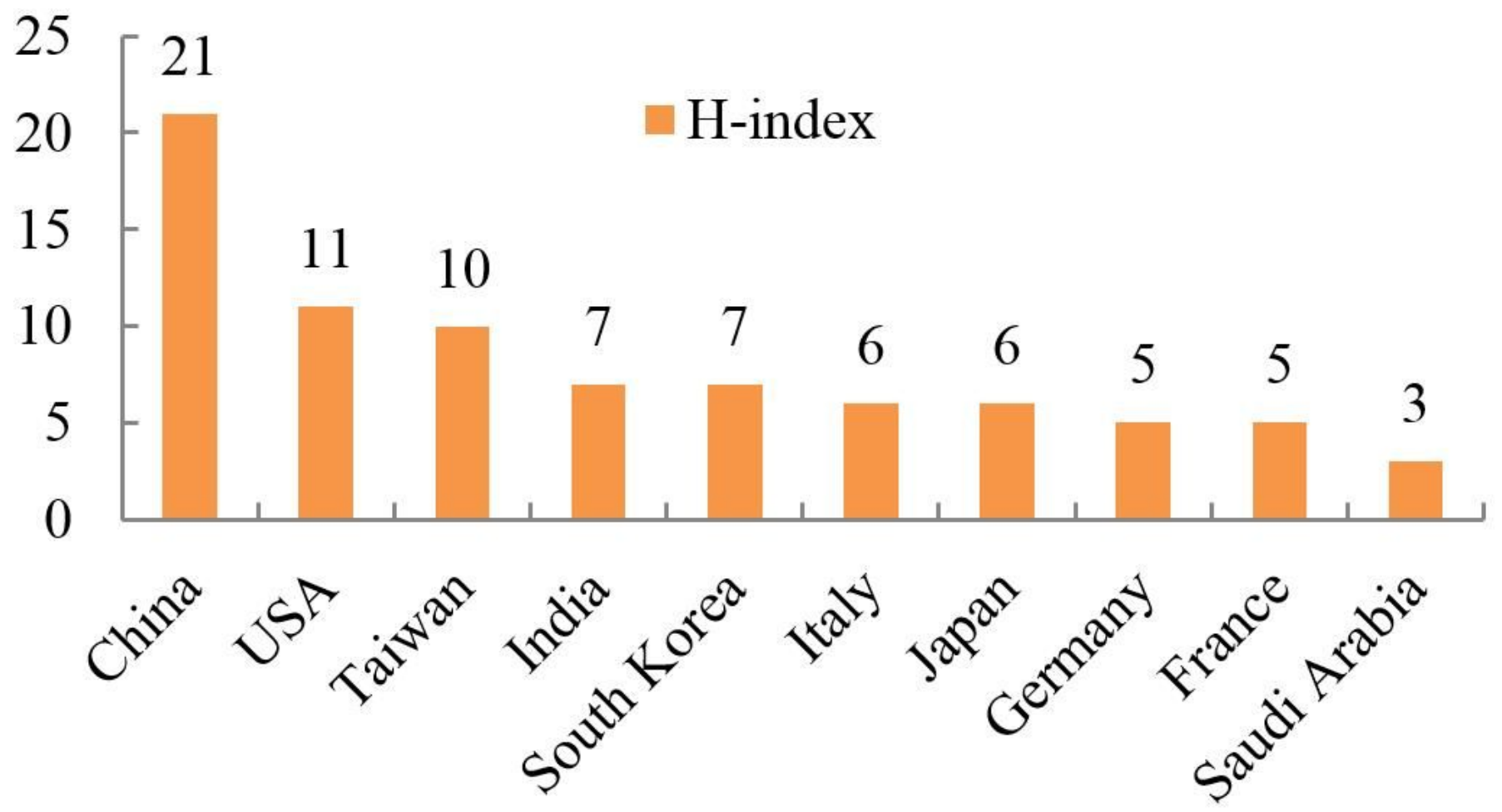

Figure 6

$\mathrm{H}$-index of publications

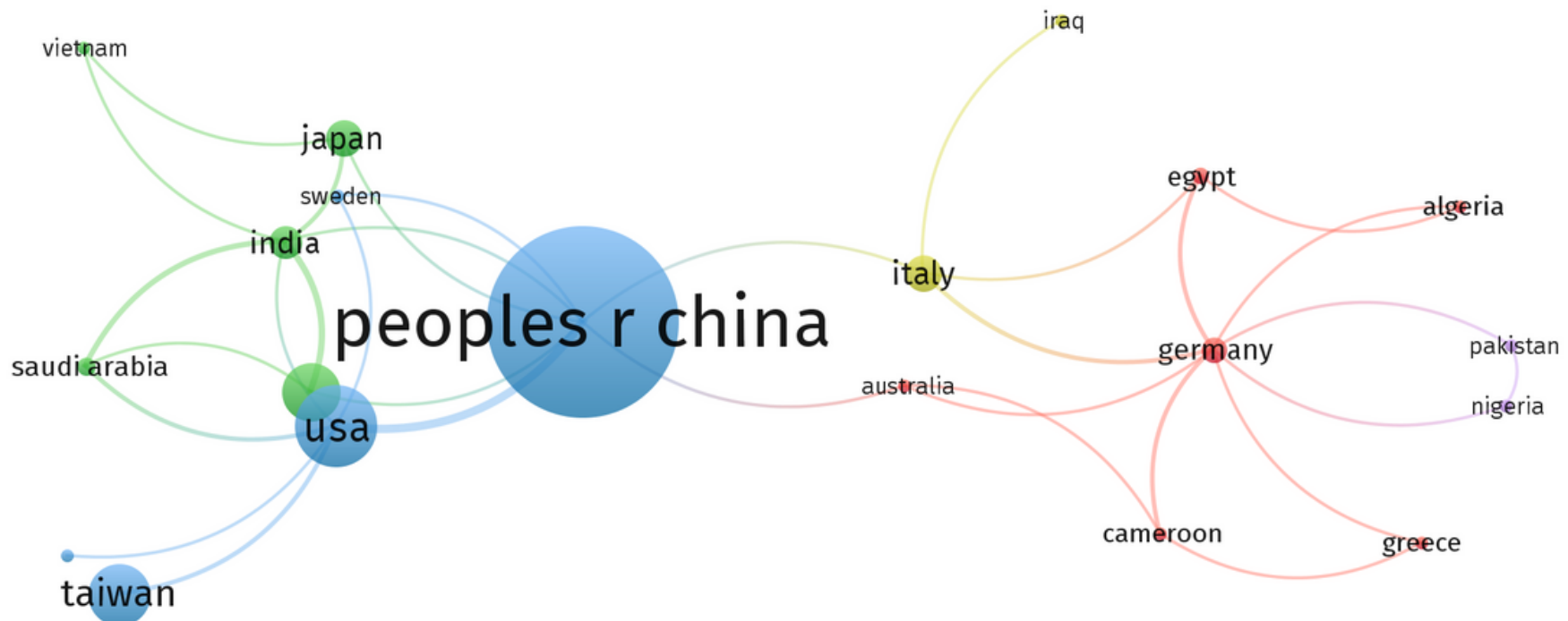

\& Vosviewer

Figure 7 


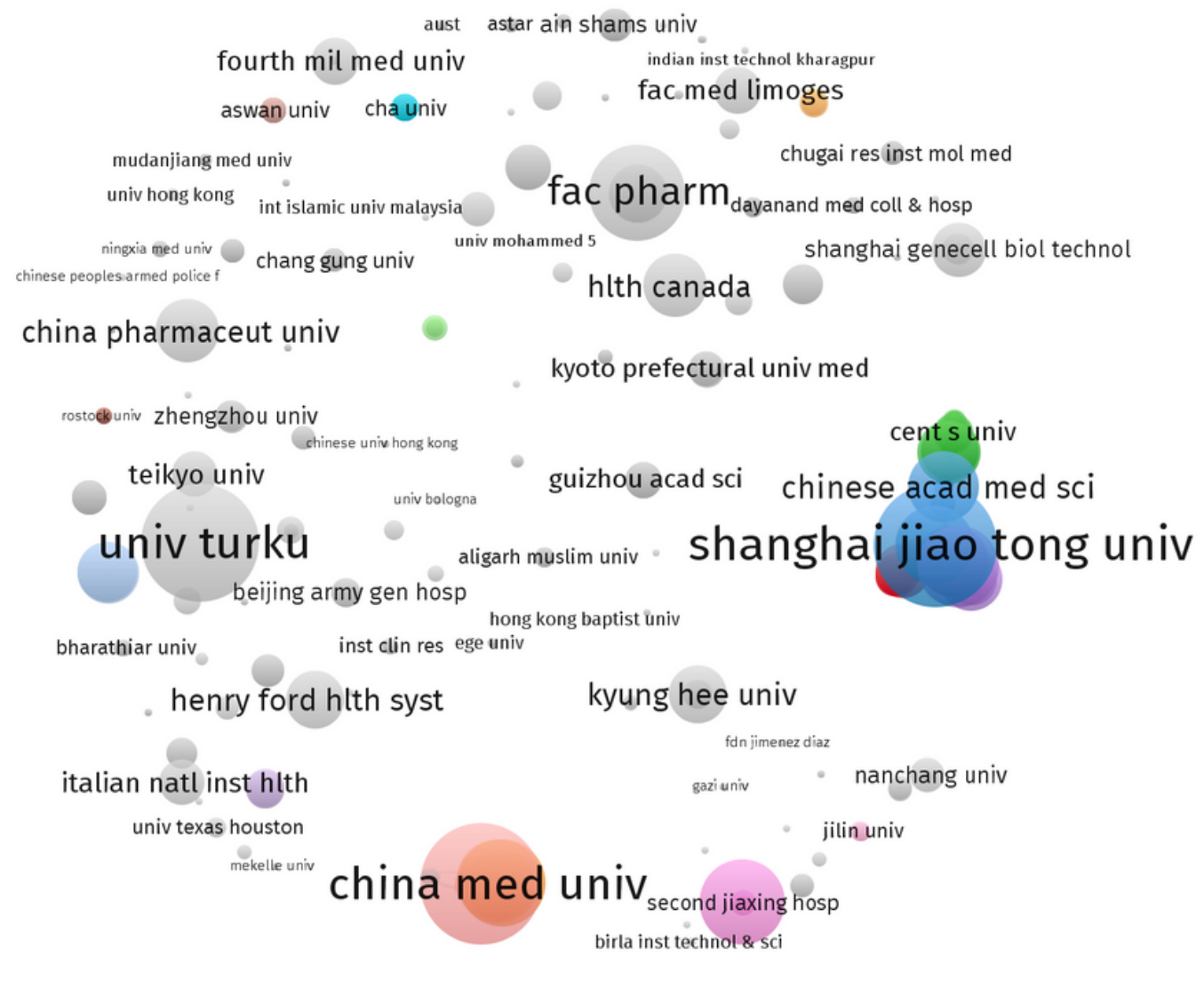

Figure 8

The institute co-authorship network of publications 


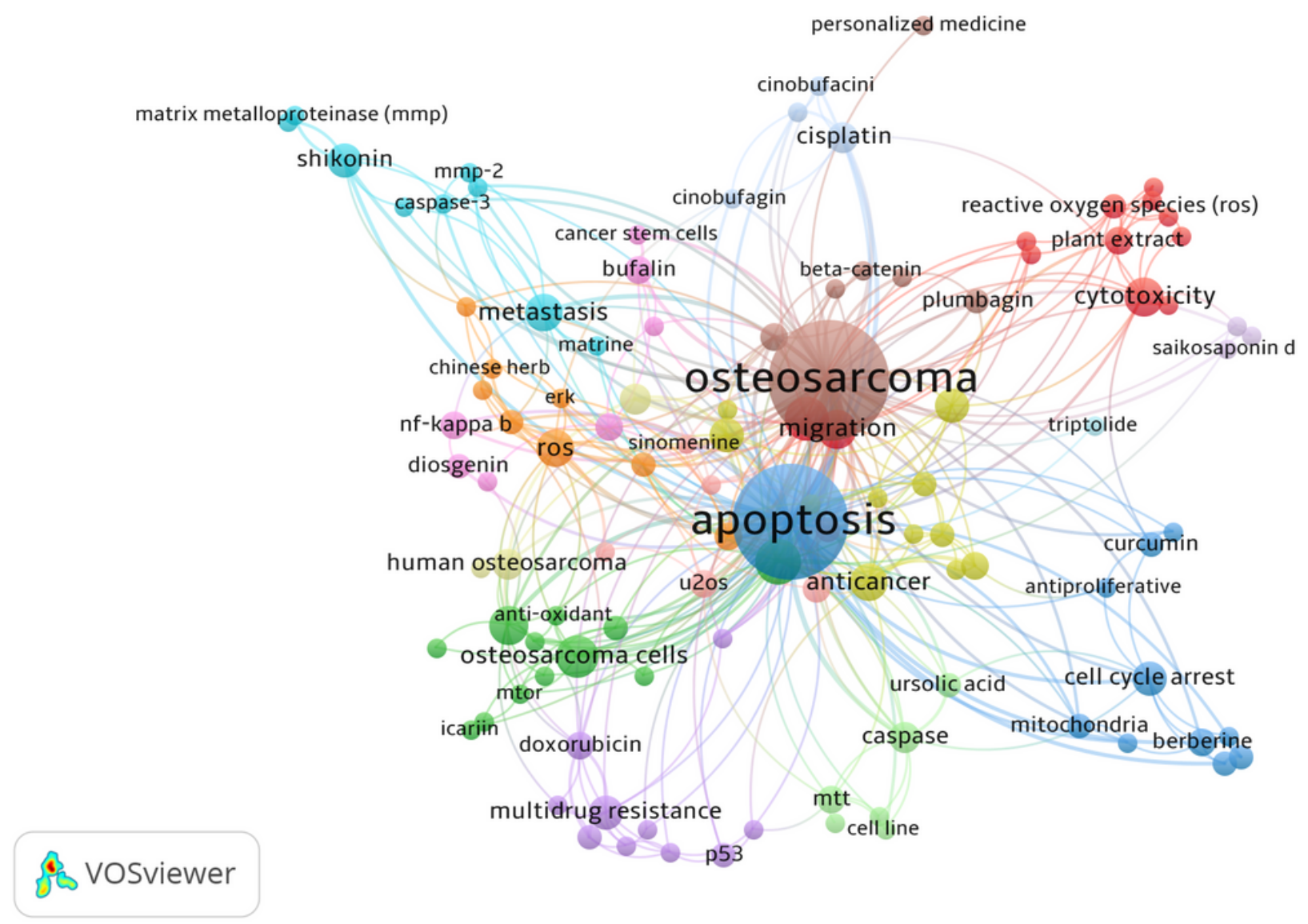

Figure 9

Keywords co-occurrence network of publications 


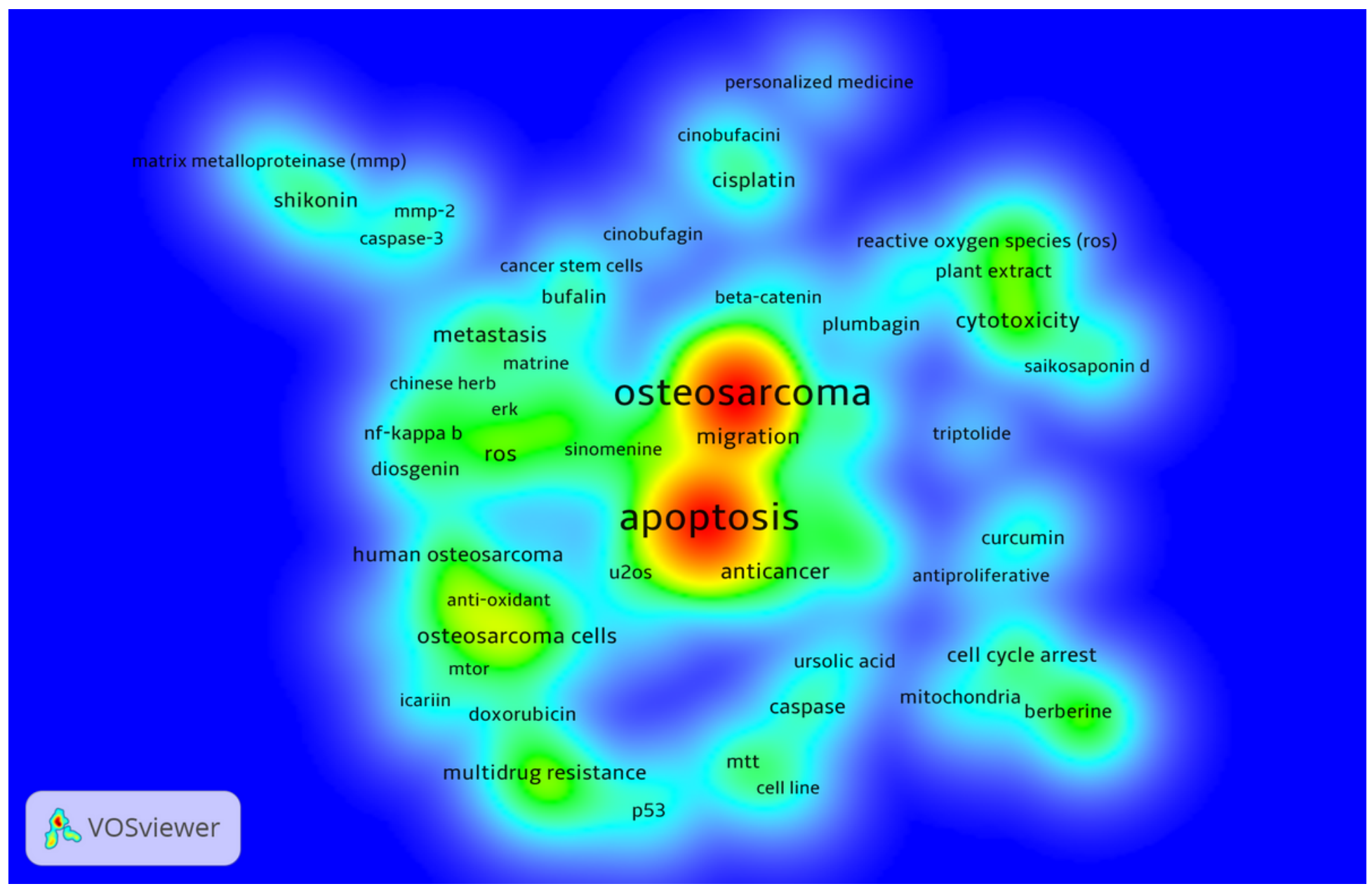

\section{Figure 10}

Keywords density visualization map of publications 


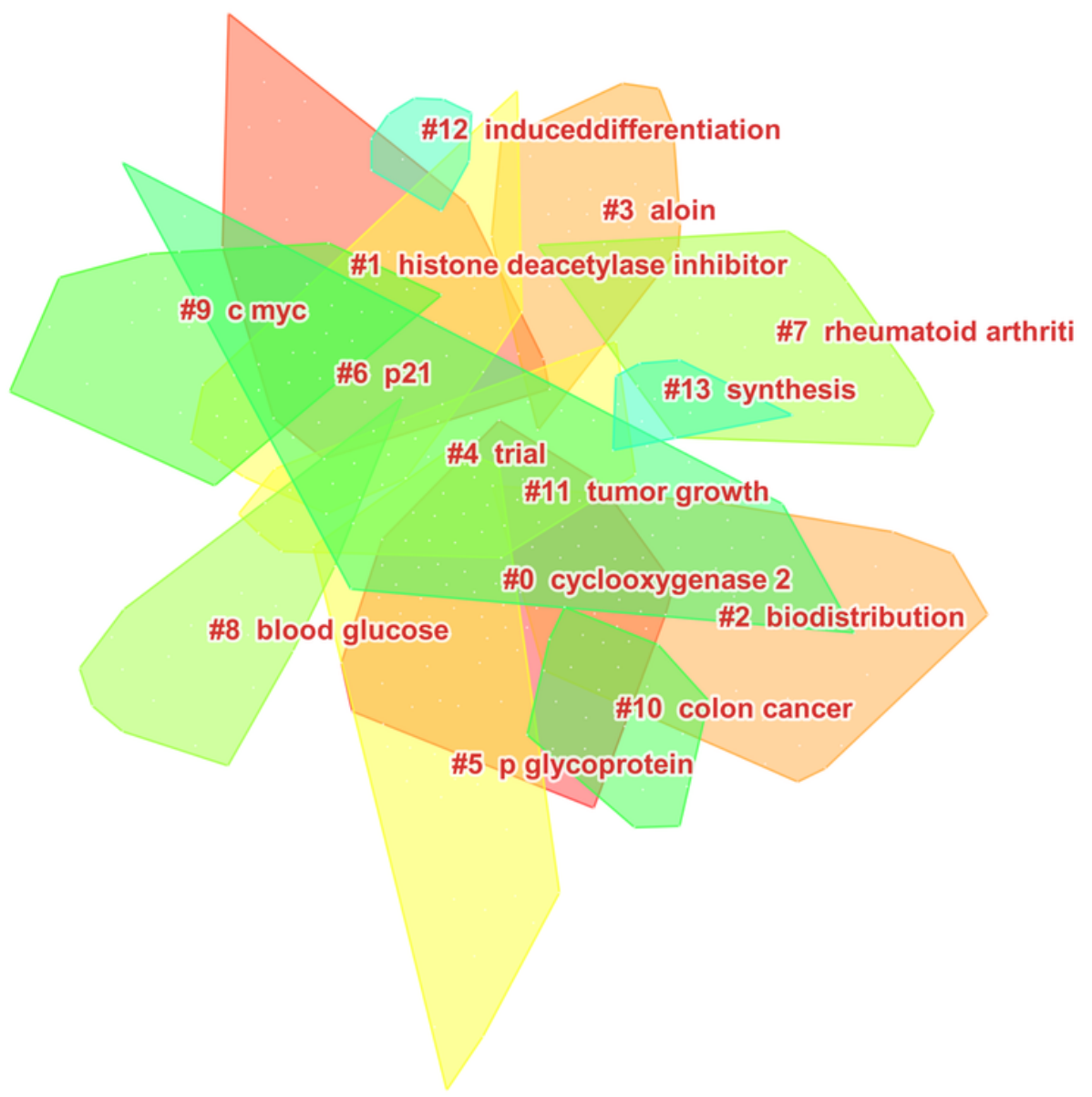

Figure 11

Clusters for high-frequency keywords of publications 


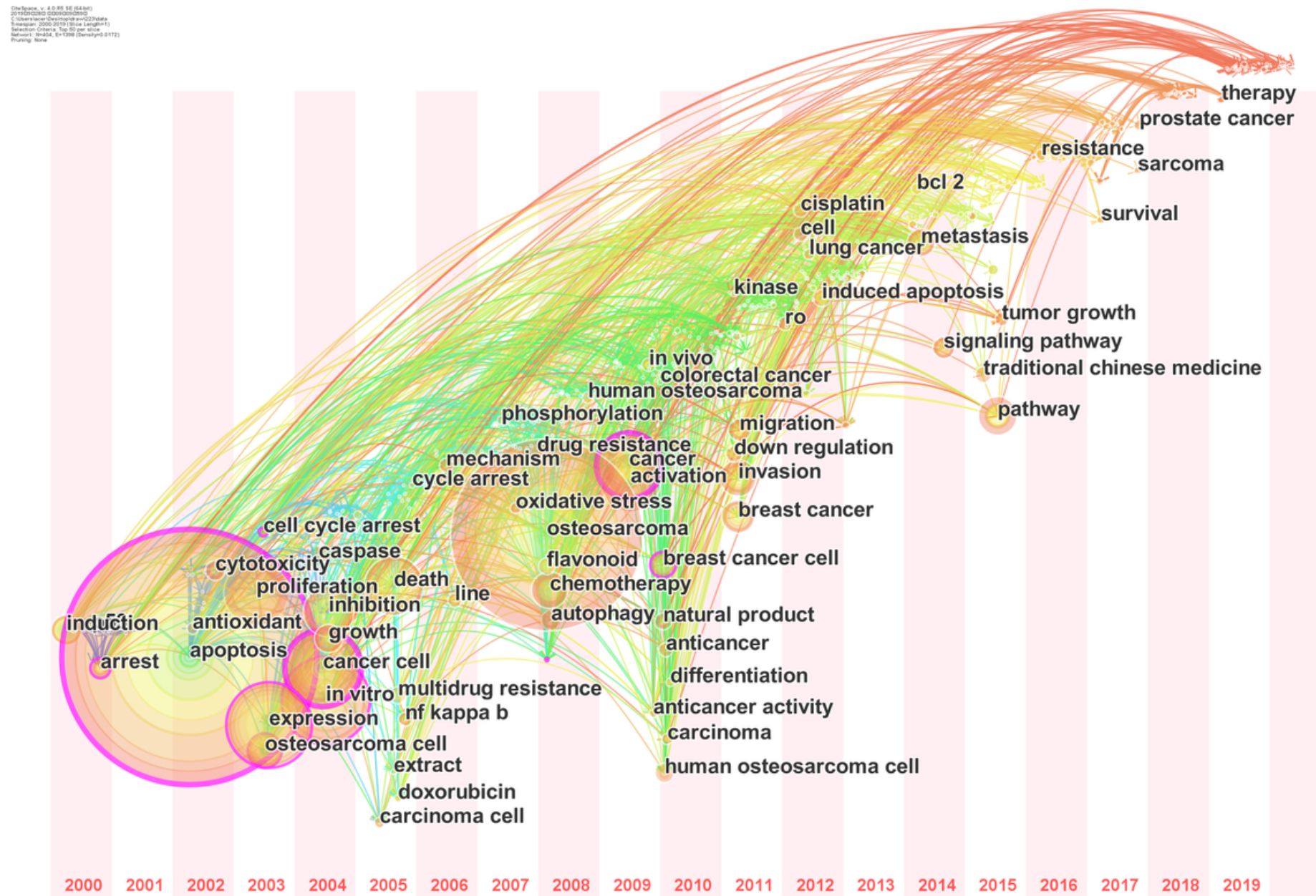

Figure 12

The keywords timeline view of publications 


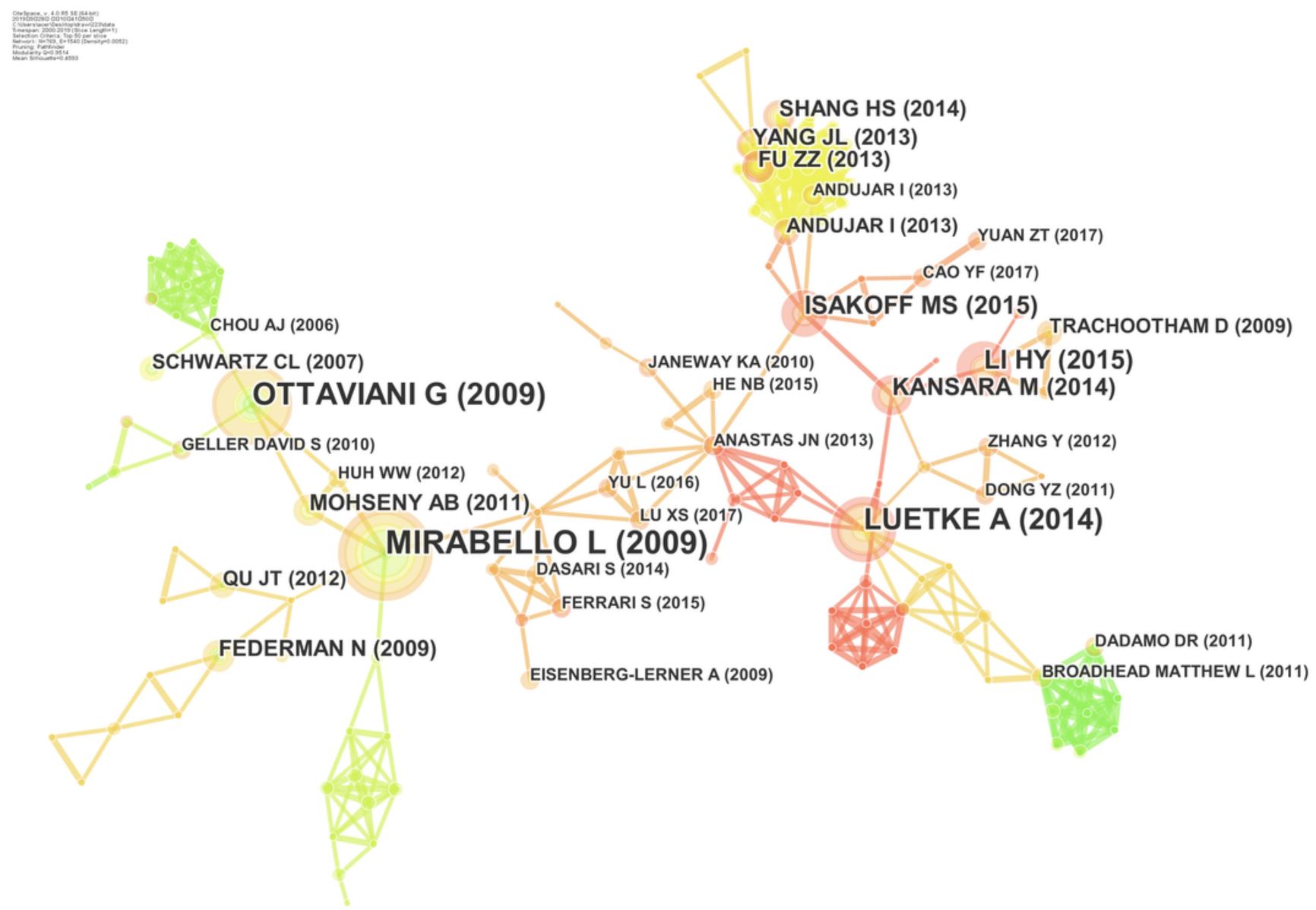

Figure 13

The reference co-citation analysis of publications 


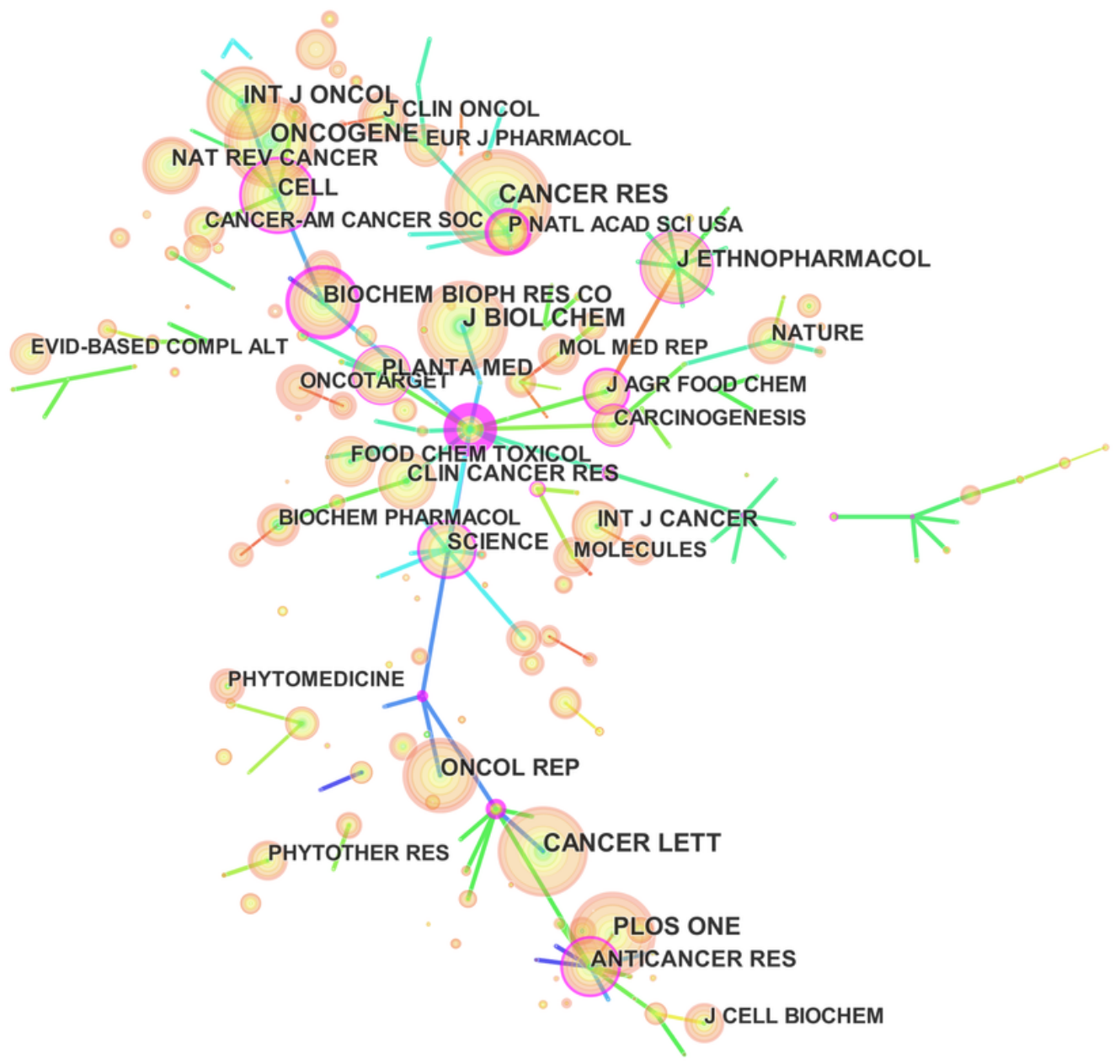

Figure 14

The journal co-citation analysis of publications 

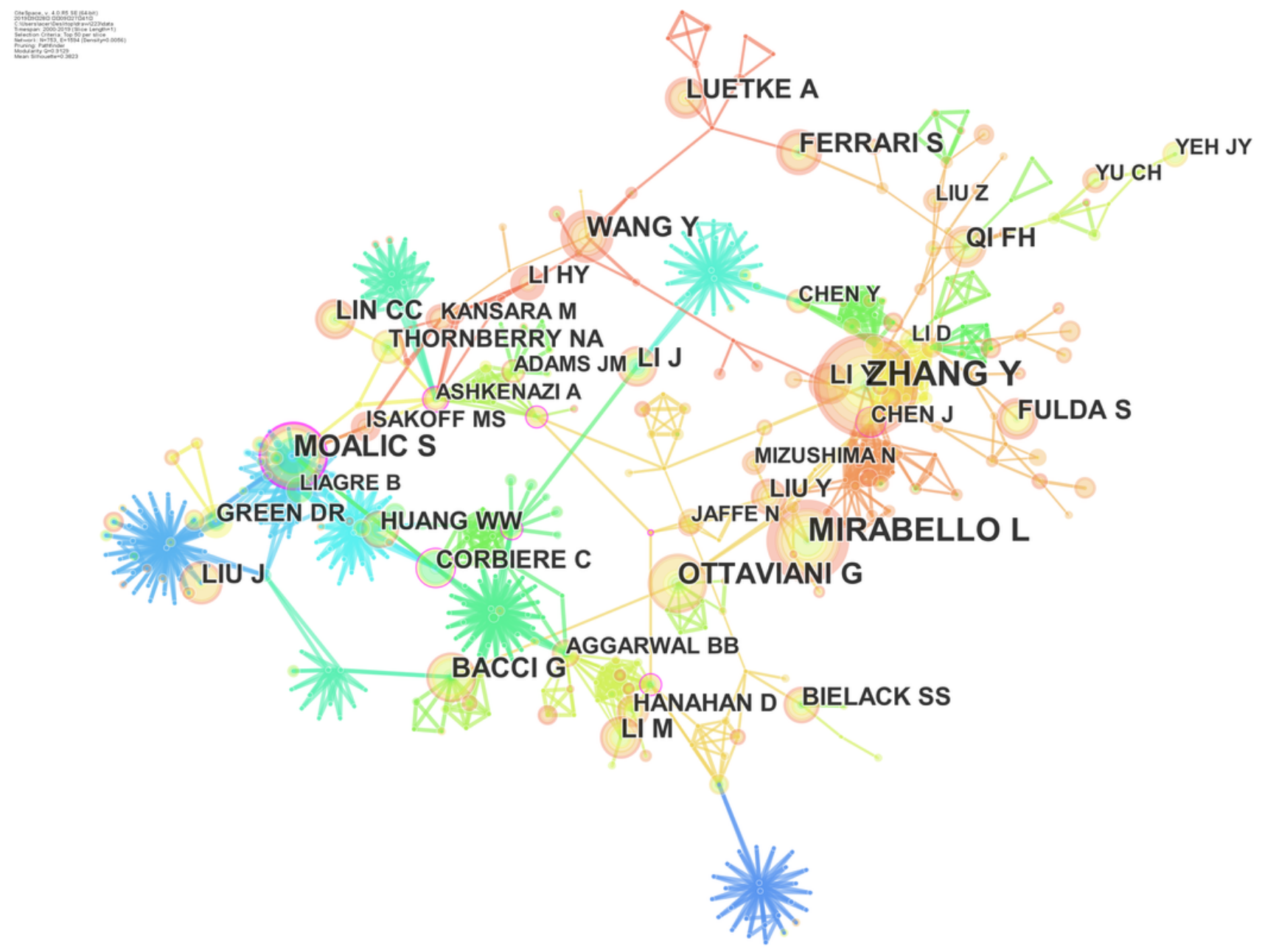

Figure 15

The author co-citation analysis of publications 